\title{
DOMINATION NUMBER, INDEPENDENT DOMINATION NUMBER AND 2-INDEPENDENCE NUMBER IN TREES
}

\author{
NASRIN DEHGARDI ${ }^{1}$ \\ Department of Mathematics and Computer Science \\ Sirjan University of Technology, Sirjan, I.R. Iran \\ e-mail: n.dehgardi@sirjantech.ac.ir \\ Seyed Mahmoud Sheikholeslami, Mina Valinavaz \\ Department of Mathematics \\ Azarbaijan Shahid Madani University, Tabriz, I.R. Iran \\ e-mail: s.m.sheikholeslami \\ m.valinavaz@azaruniv.ac.ir \\ HAMIDEH ARAM \\ Department of Mathematics \\ Gareziaeddin Center, Khoy Branch \\ Islamic Azad University, Khoy, Iran \\ e-mail: hamideh.aram@gmail.com \\ AND

\section{Lutz Volkmann} \\ Lehrstuhl II für Mathematik \\ RWTH Aachen University, 52056 Aachen, Germany \\ e-mail: volkm@math2.rwth-aachen.de
}

\begin{abstract}
For a graph $G$, let $\gamma(G)$ be the domination number, $i(G)$ be the independent domination number and $\beta_{2}(G)$ be the 2 -independence number. In this paper, we prove that for any tree $T$ of order $n \geq 2,4 \beta_{2}(T)-3 \gamma(T) \geq 3 i(T)$, and we characterize all trees attaining equality. Also we prove that for every tree $T$ of order $n \geq 2, i(T) \leq \frac{3 \beta_{2}(T)}{4}$, and we characterize all extreme trees.
\end{abstract}

\footnotetext{
${ }^{1}$ Corresponding author.
} 
Keywords: 2-independence number, domination number, independent domination number.

2010 Mathematics Subject Classification: 05C69.

\section{REFERENCES}

[1] J. Amjadi, N. Dehgardi, S.M. Sheikholeslami and M. Valinavaz, Independent Roman domination and 2-independence in trees, Discrete Math. Algorithms Appl. 10 (2018) 1850052. doi:10.1142/S1793830918500520

[2] M. Chellali, O. Favaron, A. Hansberg and L. Volkmann, $k$-domination and $k$ independence in graphs: A survey, Graphs Combin. 28 (2012) 1-55. doi:10.1007/s00373-011-1040-3

[3] M. Chellali and N. Meddah, Trees with equal 2-domination and 2-independence numbers, Discuss. Math. Graph Theory 32 (2012) 263-270. doi:10.7151/dmgt.1603

[4] N. Dehgardi, Mixed Roman domination and 2-independence in trees, Commun. Comb. Optim. 3 (2018) 79-91. doi:10.22049/CCO.2018.25964.1062

[5] O. Favaron, On a conjecture of Fink and Jacobson concerning $k$-domination and $k$-dependence, J. Combin. Theory Ser. B 39 (1985) 101-102. doi:10.1016/0095-8956(85)90040-1

[6] O. Favaron, Graduate course in the University of Blida (2005), unpublished.

[7] J.F. Fink and M.S. Jacobson, $n$-domination in graphs, in: Graph Theory with Applications to Algorithms and Computer Science (Wiley, New York, 1985) 283-300.

[8] Fink and M.S. Jacobson, On n-domination, n-dependence and forbidden subgraphs, in: Graph Theory with Applications to Algorithms and Computer Science (Wiley, New York, 1985) 301-311.

[9] A. Hansberg, D. Meierling and L. Volkmann, Independence and k-domination in graphs, Int. J. Comput. Math. 88 (2011) 905-915. doi:10.1080/00207160.2010.482664

[10] T.W. Haynes, S.T. Hedetniemi and P.J. Slater, Fundamentals of Domination in Graphs (Marcel Dekker, Inc., New York, 1998).

[11] T.W. Haynes, S.T. Hedetniemi and P.J. Slater, Domination in Graphs: Advanced Topics (Marcel Dekker, Inc., New York, 1998).

[12] M.S. Jacobson, K. Peters and D.F. Rall, On n-irredundance and n-domination, Ars Combin. 29 (1990) 151-160.

[13] N. Meddah and M. Chellali, Roman domination and 2-independence in trees, Discrete Math. Algorithms Appl. 9 (2017) 1750023.

doi:10.1142/S1793830917500239 
Received 4 July 2017

Revised 7 July 2018

Accepted 9 July 2018 